\title{
Combining both Plug-in Vehicles and Renewable Energy Resources for Unit Commitment studies in Smart Grid
}

\author{
R.A.Swief ${ }^{1}$, Mahmoud Mohey El-Din ${ }^{2}$ \\ (Electric Power \& machine Department/Ain Shams University, Cairo, Egypt) \\ (Electronics Department/The German University in Cairo.Cairo, Egypt)
}

\begin{abstract}
In this Paper, Unit commitment integration with vehicle-to-grid and Renewable Energy Resources (UC-V2G-RES) is developed. The aim of this study is to provide a cost-emission reduction solution to the smart grid. The proposed solution comprised of four steps: data clustering, economic load dispatching, sources' variables optimization and cost-emission values calculation. The Optimization is done using Genetic Algorithm (GA) to fulfill a large number of practical constraints, meet the forecast load demand calculated in advance, plus spinning reserve requirements at every time interval such that the total cost and emissions are minimum. It includes intelligently scheduling on/off states of existing generating units and large number of gridable vehicles with V2G technology in addition to time varying RESS during a full day (24 Hours). The results obtained validated to a reasonable extent the effectiveness of integrating $V 2 G$ and RESs with the smart grid. The analysis and results are presented and discussed.
\end{abstract}

Keywords: Genetic algorithms, costs, environmental management, solar power generation, wind power generation, Electric vehicles.

\section{INTRODUCTION}

Renewable energy is a clean energy source which is relatively cheap. Integrating plug-in hybrid electric vehicles (PHEVs) with vehicle-to-grid (V2G) has the capability, which can reduce emissions from the transportation sector. Linking and scheduling of Renewable Energy Sources (RESs), PHEVs (V2G Vehicles) and existing Power plants (Generation Units) is a very complex problem which needs dynamic adaptive optimization approach to optimize time-varying resources such as RESs and V2Gs in a complex smart grid, this approach is called Unit commitment (UC). The aim of this paper is to study and show the effectiveness of using PHEV-V2G as spinning reserves and RESs (Wind \& Solar) as power sources on reducing both emissions and cost. Researches in this field have mainly considered the use of PHEV-V2G either as loads, sources, or energy storages where they assumed that using PHEV-V2G have no cost, they also considered that there is no operation and maintenance cost for wind and solar power production [1]-[2], which affects the accuracy and reliability of the results.

V2G researchers have mainly concentrated on using PHEV-V2G in the ancillary services [3]. The primary contributions of this paper are as follows: (1) reliable and efficient UC with PHEV-V2G, Wind and Solar Energy (UC-V2G-RESs), (2) using PHEV-V2G as Spinning Reserve, (3) calculating the revenue of V2G to the PHEV owner when working as a Spinning Reserve only, (4) including the cost of Wind and Solar energy production in the total cost, and (5) illustration of the reduction effectiveness on both environmental and economical sides when integrating UC-V2G-RESs in Smart grid.

The rest of this paper is organized as follows. The UC-V2G-RESs problem formulation and its related constraints are presented in Section II. A dynamic adaptive optimization method to optimize intelligently timevarying resources such as RESs and V2Gs in a complex smart grid and a new simple logical Economic Load Dispatching (ELD) are described in Section III. Simulation data and results are presented and discussed in Section IV. Finally, the conclusion is given in Section V.

\subsection{Objective Function}

\section{PROBLEM ForMULATION}

The objective of the UC-V2G-RESs is to minimize both total running cost and emissions (TCE) simultaneously, as in (1), (2).

$$
\begin{aligned}
\min \mathrm{TCE} & =\min \mathrm{f}=\sum_{\mathrm{time}=1}^{\text {Hours }} \text { Fuel Cost }+ \text { Start }- \text { Up Cost }+\mathrm{V} 2 \mathrm{G} \text { (Spinning Reserve)Cost } \\
& + \text { Wind Power O\&M Cost }+ \text { Solar Power O\&M Cost } \\
& + \text { Emissions. }
\end{aligned}
$$




$$
\begin{aligned}
& \quad \operatorname{minf}=\sum_{\mathrm{i}=1}^{\mathrm{N}} \sum_{\mathrm{t}=1}^{\mathrm{H}}\left[\mathrm{FC}_{\mathrm{i}}\left(\mathrm{P}_{\mathrm{i}}(\mathrm{t})\right)+\operatorname{SUC}_{\mathrm{i}}\left(1-\mathrm{I}_{\mathrm{i}}(\mathrm{t}-1)\right)\right] \cdot \mathrm{I}_{\mathrm{i}}(\mathrm{t}) \\
& +\sum_{\mathrm{t}=1}^{\mathrm{H}} \operatorname{SRSC}(\mathrm{t}) \\
& +\sum_{\mathrm{t}=1}^{\mathrm{H}} \mathrm{W}_{\mathrm{C}}(\mathrm{t})+\sum_{\mathrm{t}=1}^{\mathrm{H}} \mathrm{S}_{\mathrm{C}}(\mathrm{t})+\sum_{\mathrm{i}=1}^{\mathrm{N}} \sum_{\mathrm{t}=1}^{\mathrm{H}} \mathcal{E} \mathcal{C}_{\mathrm{i}}\left(\mathrm{P}_{\mathrm{i}}(\mathrm{t})\right) \cdot \mathrm{I}_{\mathrm{i}}(\mathrm{t})
\end{aligned}
$$

Where, each term in (2), is the mathematical representation in (1).

. $P_{i}(t)$ is the output power from unit "i" at time " $t$ ".

$\mathrm{I}_{\mathrm{i}}(\mathrm{t})$ is the output power from V@G unit "i" at time " $\mathrm{t}$ ".

Subject to [1]-[2] constraints

\section{Constraints}

There are a number of constraints that control over the optimization process where the objective function optimization cannot violate any of these constraints as this will affect the reliability and accuracy of the results. Most of the constraints are adapted from previous studies and papers [1]-[2] so that the simulation conditions are the same and the results can be comparable.

\section{PROPSED Method}

Unit Commitment problems require a computer program to be adaptive and to continue to perform well in a changing environment with many variables to handle. The problem solving approach consists of two consecutive operations: (1) sources' variables optimization using GA, and (2) Economic Load Dispatching, as in Figure.1 gives a brief description of the two operations is given as the shown:

\section{GA Data Structure for UC-V2G-RESs}

In the proposed method, GA chromosomes structures for UC-V2G-RESs problem are as follows:

1) Binary GA: chromosomes of $0 \mathrm{~s}$ and $1 \mathrm{~s}$ for the thermal generation units is used to produce the best fit set of combinations. The best sets of combinations' fitness function are revaluated till the fitness function saturates to a certain fitness value. The best fit set contains a combination of 0 s (units are OFF) and $1 \mathrm{~s}$ (units are $\mathrm{ON}$ ) which gives the best fit value for the fitness function (lowest cost to meet the system's load demand and constraints).

2) Discrete GA: chromosomes of bits (e.g., $0,1,2,3 \ldots, \infty$ ) is used with wind and solar energy to determine their energy share to the grid so that it meets the system's constraints and achieve the best fit value (lowest cost and emissions) solution. In addition to that, discrete (integer) GA is used to determine the number of PHEVV2G that contribute to the grid's spinning reserve so that the best fit integer solution meets the system considerations and achieve the most optimized solution.

Generation units: An N x H binary matrix;

Wind energy: A 1 x H integer vector;

Solar energy: A 1 x H integer vector;

Number of vehicles: A 1 x H integer vector; 


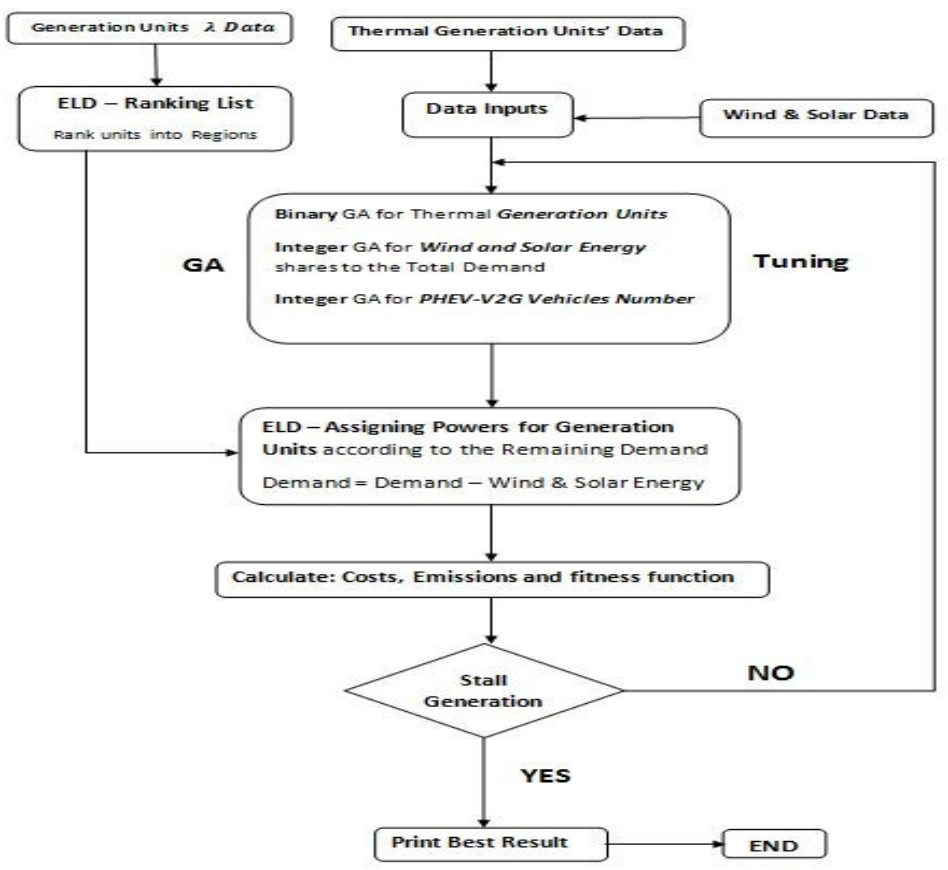

Figure 1. System flowchart.

\section{Economic Load Dispatching Calculation}

Economic Load Dispatching (ELD) is the main complex computational intensive part of unit commitment problem as stated in [2]. A New Simple Logical ELD approach is developed. The ELD is based on the units' Incremental fuel costs (Lambda $\lambda$ ) Ranking. The new ELD is composed of two operations:

3) Ranking List: where units' power ranges are divided into regions according to the change in their Lambda-Ranking, in each region the units' power are ranked in an ascending order according to their lambda $(\lambda)$.

4) Units' power assigning: load demand is satisfied by turning on the committed units according to their Ranking List (Lambda ascending order). In the first Region, the first ranked unit is contributing with power equal to the end of the region's power range and so do all the following ranked units till all the units' power reach the end limits of this region, then doing the same for the following region (according to its new different Lambda-Ranking) and so on till the load demand is satisfied.

\section{Constraints Management}

The complexity of UC-V2G-RESs using GA grows exponentially as the number of the variables and elements increases. Due to the high complexity, some constraints might be unexpectedly violated. In order not to violate the constraint, an infinity value (penalty) is assigned to each violated constraint.aint. As a result of that, an invalid infeasible solution will have a fitness value of infinity which cannot be adapted by the GA algorithm so that the GA will keep iterating till it reaches an integer value.

\section{SimUlation RESUlts}

All simulations have been run using MATLAB software. Base 10-generator system is considered for simulation with unlimited number of PHEV-V2Gs which are charged from renewable source in the owner's parking at home. In addition to the Spinning reserve revenue to the owner and in order to encourage the PHEVV2G owner to keep providing the grid with the spinning reserve service, the PHEV-V2G battery life time is taken into consideration. So the charging - discharging rate is considered 1 per day. This charging-discharging rate maintains a longer battery life time [3]. ELD- Ranking List operation for the 10-generators is done one time only before running the GA optimization algorithm which reduces the optimization complexity. Load demand, unit characteristics of the 10-unit system and emissions data are all collected from [1]-[2], capacity of each vehicle $(\mathrm{Pv})=15 \mathrm{KWh}$ and maximum battery capacity $=25 \mathrm{KWh}$; departure state of charge, SoC $(\Psi)=60 \%$; efficiency of the converter $(\eta)=85 \%$ and charging-discharging rate $=1$ per day. In order to perform simulations on the same condition of [1]-[2], the spinning reserve requirement is assumed to be a minimum of $10 \%$ of the load demand and the total scheduling period is 24 hours. Prices for using PHEV-V2G as spinning reserve (owner's revenue) is collected from CAISO's Spinning Reserve cost (SRC) for electricity [4] and costs for Wind $\left(\mathrm{C}_{\mathrm{W}}\right)$ and Solar $\left(\mathrm{C}_{\mathrm{S}}\right)$ Energy is collected from California's O\&M (fixed + variable) cost for Wind and Solar [5]. Wind and Solar 
penetration level (power share) of the load is weighted and adapted according to the Wind \& Solar energy generation to the grid's load ratio for CAISO in Fall 2012 [6] so that the load demand to Wind \& Solar energy ratio in our model would be the same as the ratio in [6]. In TABLE I, Wind \& Solar power share to our model and generation to load ratio for CAISO is listed.

Simulation results for unit commitment of the thermal generation units only are shown in TABLE II. The effectiveness of integrating PHEV-V2G with the 10-base generation units and the reduction effects in both emissions and cost are shown in TABLE III. In TABLE IV, results of unit commitment for the 10-base generation units integrated with wind and solar energy is shown.

The total running cost for the base 10 -generator system is $563937 \$$ and it lowers to $557690 \$$ when integrating PHEVs-V2G as a spinning reserve service provider. Integrating PHEVs-V2G to the smart electricity grid as a spinning reserve service provider affects both the cost and emissions. Simulation results has shown significant reduction in both fuel cost and total cost when using PHEVs-V2G, achieving 12277 \$ reduction in fuel cost and $6247 \$$ in total cost per day taking into consideration that using PHEVs-V2G bring 5858.1\$ as a revenue to the owners. The revenue is considered as a source of attraction to encourage the PHEVs-V2G owners to be more involved in using their own vehicles as a spinning reserve service provider and as a compensation for their time and battery usage. Emissions reduced as well by 422 tons/day when using PHEVs-V2G taking into consideration that cost reduction has a higher priority than emissions reduction in our simulations.

table i. Power Share and Generation to load Ratio for Wind \& Solar Energy.

\begin{tabular}{|c|c|c|c|c|}
\hline Hours & $\begin{array}{c}\text { Wind-Load } \\
\text { Ratio }\end{array}$ & $\begin{array}{c}\text { Max. Wind } \\
\text { Level }\end{array}$ & $\begin{array}{c}\text { Solar -Load } \\
\text { Ratio }\end{array}$ & $\begin{array}{c}\text { Max. Solar } \\
\text { Level }\end{array}$ \\
\hline 1 & 0.0929 & 65 & 0 & 0 \\
\hline 2 & 0.0950 & 71.25 & 0 & 0 \\
\hline 3 & 0.0974 & 82.76 & 0 & 0 \\
\hline 4 & 0.0947 & 90 & 0 & 0 \\
\hline 5 & 0.0897 & 89.74 & 0 & 0 \\
\hline 6 & 0.0756 & 83.17 & 0 & 0 \\
\hline 7 & 0.0652 & 75 & 0.0043 & 5 \\
\hline 8 & 0.0592 & 71.02 & 0.0184 & 22.04 \\
\hline 9 & 0.0474 & 61.66 & 0.0415 & 53.95 \\
\hline 10 & 0.0389 & 54.44 & 0.0481 & 67.4 \\
\hline 11 & 0.0393 & 56.96 & 0.0464 & 67.32 \\
\hline 12 & 0.0464 & 69.64 & 0.0464 & 69.64 \\
\hline 13 & 0.0518 & 72.5 & 0.0464 & 65 \\
\hline 14 & 0.0517 & 67.24 & 0.0448 & 58.27 \\
\hline 15 & 0.0586 & 70.34 & 0.0448 & 53.79 \\
\hline 16 & 0.0621 & 65.17 & 0.0448 & 47.06 \\
\hline 17 & 0.0610 & 61.01 & 0.0271 & 27.11 \\
\hline 18 & 0.0633 & 69.66 & 0.0100 & 11 \\
\hline 19 & 0.0639 & 76.72 & 0 & 0 \\
\hline 20 & 0.0645 & 90.32 & 0 & 0 \\
\hline 21 & 0.0633 & 82.33 & 0 & 0 \\
\hline 22 & 0.0684 & 75.26 & 0 & 0 \\
\hline 23 & 0.0784 & 70.58 & 0 & 0 \\
\hline 24 & 0.0870 & 69.56 & 0 & 0 \\
\hline & & & & \\
\hline
\end{tabular}

Integrating both wind and solar energy as power sources to partially replace thermal generation units' power share to the grid affects both cost and emissions. Although, wind and solar energy production related costs are considered relatively high and that there is a gradual decrease in the O\&M prices, the reductions in both cost and emissions are very encouraging. Integrating wind \& solar energy reduced the total cost to be $554436 \$$ and emissions to 24612 tons/day. Reductions in both fuel cost and total cost are significant, fuel cost is reduced by $39550 \$$ when integrating wind \& solar energy to the base 10 -generators system model and total cost is reduced by $9501 \$$ taking into consideration that wind energy production related cost is $21166 \$$ and solar energy production related cost is $8933 \$$.

Significant reduction in emissions is achieved when using RESs as power sources, emissions were at the level of 24612 tons/day which makes a reduction by 2379 tons/day taking into consideration that emissions reduction was given a higher priority than cost reduction in the simulation (emissions-high priority simulation). Due to the relatively high production cost [5] for solar energy $(47.03 \$ / \mathrm{MW})$ over wind energy $(12.17 \$ / \mathrm{MW})$ and even thermal generation units, the solar energy share to satisfy the load demand is the lowest among the three power sources. 
Combining both Plug-in Vehicles and Renewable Energy Resources for Unit Commitment studies in

TABLE II. BAse 10-Thermal Gener ation units Simulation Resullts. COSts and Emmissions

\begin{tabular}{|c|c|c|c|c|c|c|c|c|c|c|c|c|c|}
\hline Hours & $\begin{array}{c}\text { U1 } \\
\text { MW }\end{array}$ & $\begin{array}{c}\text { U2 } \\
\text { MW }\end{array}$ & $\begin{array}{l}\text { U3 } \\
\text { MW }\end{array}$ & $\begin{array}{c}\text { U4 } \\
\text { MW }\end{array}$ & $\begin{array}{c}\text { U5 } \\
\text { MW }\end{array}$ & $\begin{array}{c}\text { U6 } \\
\text { MW }\end{array}$ & $\begin{array}{c}\text { U7 } \\
\text { MW }\end{array}$ & $\begin{array}{l}\text { U8 } \\
\text { MW }\end{array}$ & $\begin{array}{c}\text { U9 } \\
\text { MW }\end{array}$ & $\begin{array}{l}\text { U10 } \\
\text { MW }\end{array}$ & $\begin{array}{c}\text { Demand } \\
\mathrm{MW}\end{array}$ & $\begin{array}{c}\text { Reserve } \\
\mathrm{MW}\end{array}$ & $\begin{array}{c}\text { Reserve } \\
\%\end{array}$ \\
\hline 1 & 455 & 245 & 0 & 0 & 0 & 0 & 0 & 0 & 0 & 0 & 700 & 210 & 30 \\
\hline 2 & 455 & 295 & 0 & 0 & 0 & 0 & 0 & 0 & 0 & 0 & 750 & 160 & 21.33 \\
\hline 3 & 455 & 370 & 0 & 0 & 25 & 0 & 0 & 0 & 0 & 0 & 850 & 222 & 26.12 \\
\hline 4 & 455 & 455 & 0 & 0 & 40 & 0 & 0 & 0 & 0 & 0 & 950 & 122 & 12.84 \\
\hline 5 & 455 & 390 & 0 & 130 & 25 & 0 & 0 & 0 & 0 & 0 & 1000 & 202 & 20.2 \\
\hline 6 & 455 & 360 & 130 & 130 & 25 & 0 & 0 & 0 & 0 & 0 & 1100 & 232 & 21.09 \\
\hline 7 & 455 & 410 & 130 & 130 & 25 & 0 & 0 & 0 & 0 & 0 & 1150 & 182 & 15.83 \\
\hline 8 & 455 & 455 & 130 & 130 & 30 & 0 & 0 & 0 & 0 & 0 & 1200 & 132 & 11 \\
\hline 9 & 455 & 455 & 130 & 130 & 85 & 20 & 25 & 0 & 0 & 0 & 1300 & 197 & 15.15 \\
\hline 10 & 455 & 455 & 130 & 130 & 162 & 33 & 25 & 10 & 0 & 0 & 1400 & 152 & 10.86 \\
\hline 11 & 455 & 455 & 130 & 130 & 162 & 73 & 25 & 10 & 10 & 0 & 1450 & 157 & 10.83 \\
\hline 12 & 455 & 455 & 130 & 130 & 162 & 80 & 25 & 43 & 10 & 10 & 1500 & 162 & 10.8 \\
\hline 13 & 455 & 455 & 130 & 130 & 162 & 33 & 25 & 10 & 0 & 0 & 1400 & 152 & 10.86 \\
\hline 14 & 455 & 455 & 130 & 130 & 85 & 20 & 25 & 0 & 0 & 0 & 1300 & 197 & 15.15 \\
\hline 15 & 455 & 455 & 130 & 130 & 30 & 0 & 0 & 0 & 0 & 0 & 1200 & 132 & 11 \\
\hline 16 & 455 & 310 & 130 & 130 & 25 & 0 & 0 & 0 & 0 & 0 & 1050 & 282 & 26.86 \\
\hline 17 & 455 & 260 & 130 & 130 & 25 & 0 & 0 & 0 & 0 & 0 & 1000 & 332 & 33.2 \\
\hline 18 & 455 & 360 & 130 & 130 & 25 & 0 & 0 & 0 & 0 & 0 & 1100 & 232 & 21.09 \\
\hline 19 & 455 & 455 & 130 & 130 & 30 & 0 & 0 & 0 & 0 & 0 & 1200 & 132 & 11 \\
\hline 20 & 455 & 455 & 130 & 130 & 162 & 33 & 25 & 10 & 0 & 0 & 1400 & 152 & 10.86 \\
\hline 21 & 455 & 455 & 130 & 130 & 85 & 20 & 25 & 0 & 0 & 0 & 1300 & 197 & 15.15 \\
\hline 22 & 455 & 455 & 0 & 0 & 145 & 20 & 25 & 0 & 0 & 0 & 1100 & 137 & 12.45 \\
\hline 23 & 455 & 425 & 0 & 0 & 0 & 20 & 0 & 0 & 0 & 0 & 900 & 90 & 10 \\
\hline 24 & 455 & 345 & 0 & 0 & 0 & 0 & 0 & 0 & 0 & 0 & 800 & 110 & 13.75 \\
\hline \multicolumn{3}{|c|}{ Fuel Cost } & \multicolumn{4}{|c|}{ Start Up Cost } & \multicolumn{4}{|c|}{ Total Cost } & \multicolumn{3}{|c|}{ Emissions } \\
\hline \multicolumn{3}{|c|}{$559847 \$$} & \multicolumn{4}{|c|}{$4090 \$$} & \multicolumn{4}{|c|}{$563937 \$$} & \multicolumn{3}{|c|}{26991 tons } \\
\hline
\end{tabular}

TABLE III. PHEVS-V2G INTEGRATION AS A SPINNING RESERVE SERVICE PROVIDER'S SIMULATION RESULTS, COSTS AND EMMISSIONS

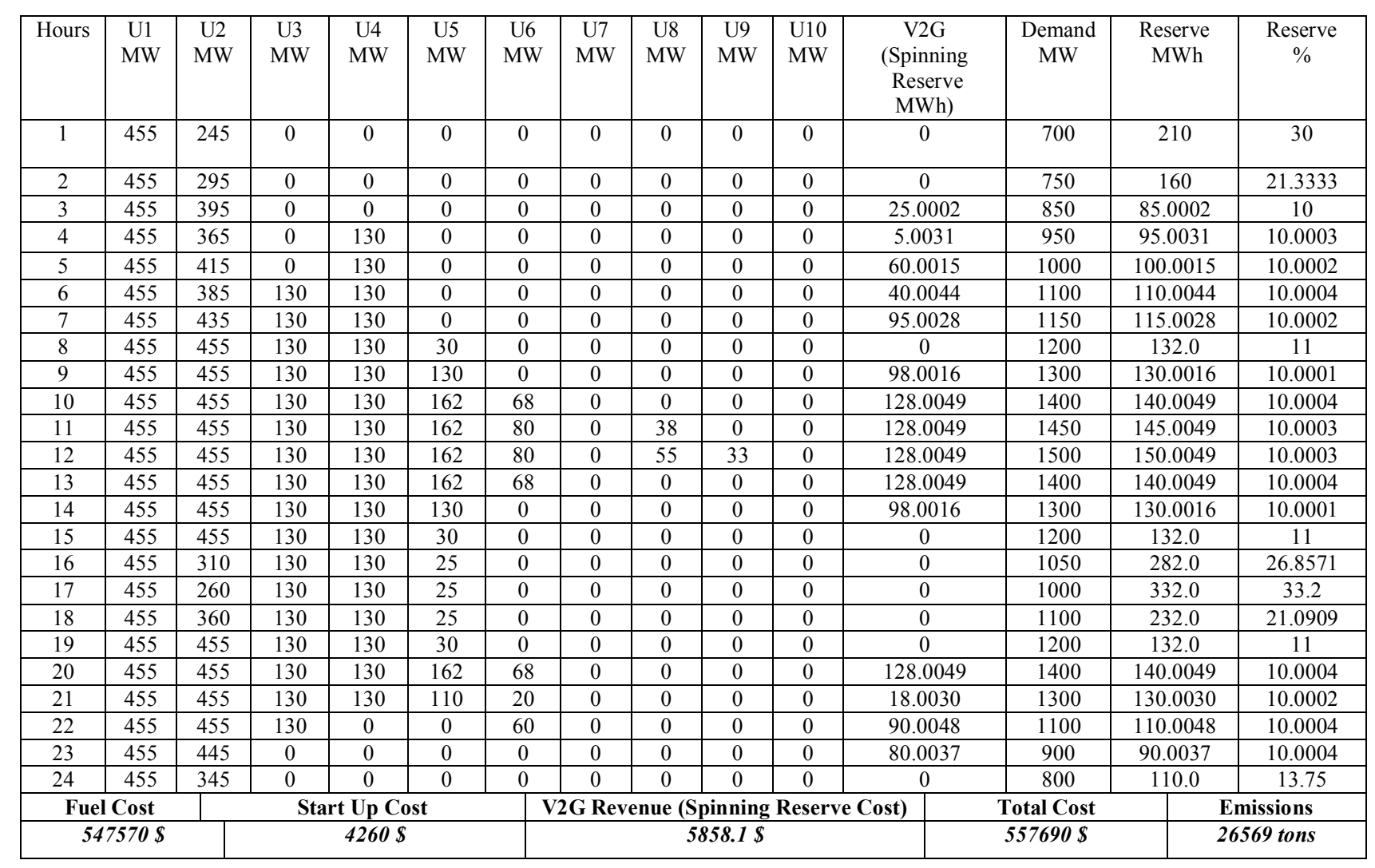


Combining both Plug-in Vehicles and Renewable Energy Resources for Unit Commitment studies in

TABLE IV. Wind \& SOlar Integration to the BASE 10-Generators Model Simulation RESUlts, Costs AND EMMISSIONS

\begin{tabular}{|c|c|c|c|c|c|c|c|c|c|c|c|c|c|c|c|}
\hline Hours & $\begin{array}{c}\text { U1 } \\
\text { MW }\end{array}$ & $\begin{array}{c}\text { U2 } \\
\text { MW }\end{array}$ & $\begin{array}{c}\text { U3 } \\
\text { MW }\end{array}$ & $\begin{array}{c}\text { U4 } \\
\text { MW }\end{array}$ & $\begin{array}{c}\text { U5 } \\
\text { MW }\end{array}$ & $\begin{array}{c}\text { U6 } \\
\text { MW }\end{array}$ & $\begin{array}{c}\text { U7 } \\
\text { MW }\end{array}$ & $\begin{array}{c}\text { U8 } \\
\text { MW }\end{array}$ & $\begin{array}{c}\text { U9 } \\
\text { MW }\end{array}$ & $\begin{array}{l}\text { U10 } \\
\text { MW }\end{array}$ & $\begin{array}{l}\text { Solar } \\
\text { MW }\end{array}$ & $\begin{array}{l}\text { Wind } \\
\text { MW }\end{array}$ & $\begin{array}{c}\text { Demand } \\
\text { MW }\end{array}$ & $\begin{array}{c}\text { Reserve } \\
\text { MWh }\end{array}$ & $\begin{array}{c}\text { Reserve } \\
\%\end{array}$ \\
\hline 1 & 455 & 180 & 0 & 0 & 0 & 0 & 0 & 0 & 0 & 0 & 0 & 65 & 700 & 275 & 43 \\
\hline 2 & 455 & 224 & 0 & 0 & 0 & 0 & 0 & 0 & 0 & 0 & 0 & 71 & 750 & 231 & 34 \\
\hline 3 & 455 & 287 & 0 & 0 & 25 & 0 & 0 & 0 & 0 & 0 & 0 & 83 & 850 & 305 & 40 \\
\hline 4 & 455 & 380 & 0 & 0 & 25 & 0 & 0 & 0 & 0 & 0 & 0 & 90 & 950 & 212 & 24.6 \\
\hline 5 & 455 & 300 & 130 & 0 & 25 & 0 & 0 & 0 & 0 & 0 & 0 & 90 & 1000 & 292 & 32 \\
\hline 6 & 455 & 407 & 130 & 0 & 25 & 0 & 0 & 0 & 0 & 0 & 0 & 83 & 1100 & 185 & 18 \\
\hline 7 & 455 & 330 & 130 & 130 & 25 & 0 & 0 & 0 & 0 & 0 & 5 & 75 & 1150 & 262 & 24.5 \\
\hline 8 & 455 & 367 & 130 & 130 & 25 & 0 & 0 & 0 & 0 & 0 & 22 & 71 & 1200 & 225 & 20 \\
\hline 9 & 455 & 455 & 130 & 130 & 48 & 20 & 0 & 0 & 0 & 0 & 0 & 62 & 1300 & 174 & 14 \\
\hline 10 & 455 & 455 & 130 & 130 & 121 & 20 & 25 & 0 & 10 & 0 & 0 & 54 & 1400 & 206 & 15 \\
\hline 11 & 455 & 455 & 130 & 130 & 158 & 20 & 25 & 0 & 10 & 10 & 0 & 57 & 1450 & 214 & 15.4 \\
\hline 12 & 455 & 455 & 130 & 130 & 162 & 53 & 25 & 10 & 10 & 0 & 0 & 70 & 1500 & 177 & 12 \\
\hline 13 & 455 & 455 & 130 & 130 & 47.5 & 20 & 25 & 0 & 0 & 0 & 65 & 72.5 & 1400 & 234.5 & 18.6 \\
\hline 14 & 455 & 390 & 130 & 130 & 25 & 20 & 25 & 0 & 0 & 0 & 58 & 67 & 1300 & 322 & 27.4 \\
\hline 15 & 455 & 389 & 130 & 130 & 25 & 0 & 0 & 0 & 0 & 0 & 1 & 70 & 1200 & 203 & 18 \\
\hline 16 & 455 & 244 & 130 & 130 & 25 & 0 & 0 & 0 & 0 & 0 & 1 & 65 & 1050 & 348 & 35.4 \\
\hline 17 & 455 & 172 & 130 & 130 & 25 & 0 & 0 & 0 & 0 & 0 & 27 & 61 & 1000 & 420 & 46 \\
\hline 18 & 455 & 279 & 130 & 130 & 25 & 0 & 0 & 0 & 0 & 0 & 11 & 70 & 1100 & 313 & 31 \\
\hline 19 & 455 & 383 & 130 & 130 & 25 & 0 & 0 & 0 & 0 & 0 & 0 & 77 & 1200 & 209 & 18.6 \\
\hline 20 & 455 & 455 & 130 & 130 & 95 & 20 & 25 & 0 & 0 & 0 & 0 & 90 & 1400 & 187 & 14 \\
\hline 21 & 455 & 433 & 130 & 130 & 25 & 20 & 25 & 0 & 0 & 0 & 0 & 82 & 1300 & 279 & 22 \\
\hline 22 & 455 & 455 & 0 & 0 & 70 & 20 & 25 & 0 & 0 & 0 & 0 & 75 & 1100 & 212 & 20.7 \\
\hline 23 & 455 & 349 & 0 & 0 & 25 & 0 & 0 & 0 & 0 & 0 & 0 & 71 & 900 & 242.6 & 29 \\
\hline 24 & 455 & 275 & 0 & 0 & 0 & 0 & 0 & 0 & 0 & 0 & 0 & 70 & 800 & 179.6 & 24.6 \\
\hline \multicolumn{2}{|c|}{$\begin{array}{l}\text { Fuel } \\
\text { Cost }\end{array}$} & \multicolumn{2}{|c|}{$\begin{array}{c}\text { Start Up } \\
\text { Cost }\end{array}$} & \multicolumn{4}{|c|}{ Solar Energy Cost } & \multicolumn{4}{|c|}{ Wind Energy Cost } & \multicolumn{2}{|c|}{ Emissions } & \multicolumn{2}{|c|}{ Total Cost } \\
\hline \multicolumn{2}{|c|}{$520297 \$$} & \multicolumn{2}{|l|}{$4040 \$$} & \multicolumn{3}{|c|}{$8933 \$$} & & \multicolumn{3}{|c|}{$21166 \$$} & & \multicolumn{2}{|c|}{24612 tons } & \multicolumn{2}{|c|}{$554436 \$$} \\
\hline
\end{tabular}

Depending on the simulation conditions and reduction priorities, the use of solar energy can be constructive or destructive to the final results. When adjusting the simulation settings to set cost reduction as high priority, the GA optimization iteratively lower the solar power share to the grid so that the best fit total cost is achieved. Cost-high priority simulation achieve a total cost of 547990\$/day which is lower than emissionhigh priority simulation by $6446 \$$ day. The cost reduction effect is due to lowering the solar energy share to the load by $181 \mathrm{MW} /$ day as its cost is the highest among all the other power sources.

The spinning reserve (SR) percentage is one of the most important elements in a UC problem optimization. Figure. 2 shows three curves represent the SR percentages for the three modes of simulation. PHEVs-V2G integration gives a full and immediate control of the SR percentage over the day. This can be shown in the period from 3:00 to 15:00 where a SR percentage is almost exactly 10\% of the load. SR control ability is expensive and takes more time when thermal generation units are used, but when using PHEVs-V2G it provide full and quick response when needed and saves money when there is no need. The average SR percentage varied over the three modes. For the base 10-units, the average SR percentage is: $16.6 \%$ of the load, then it lowers to: $13.7 \%$ of load for the PHEVs-V2G integration. The reduction in the average SR percentage is due to the controllability that PHEVs-V2G offer according to the adjustments (Simulation settings: SR percentage is a minimum of $10 \%$ ). The average SR percentage increases significantly where the average SR is: $24.9 \%$ of load when integrating wind \& solar energy which makes the system more stable and reliable. The relatively high average SR percentage compensates for the wind and solar day ahead forecasting error which ranges from $5 \%$ to $20 \%$ of wind \& solar energy shared [8]. The uncertainty of wind and solar energy is dependent on many variables such as: geographical area, forecasting models used and period-ahead forecasting, all of these variables affect the uncertainty percentage and the overall accuracy.

As a result of that, two methods were considered to handle the uncertainty challenge:

(1) The total penetration level of wind \& solar energy is less than or equal to $15 \%$ of the load demand (average of: $6 \%$ wind to load and $1 \%$ solar to load) Table. I.

(2) SR percentage up leveling ranges from $12 \%$ to $46 \%$ of load with an average of $24.9 \%$. Further enhancement can be done to increase the SR percentage, reliability and stability of the system besides covering up any unexpected uncertainty error for wind and solar energy which includes integrating both PHEV-V2G and RESs (wind \& solar energy). 
Integrating PHEVs-V2G and RESs slightly increases the cost and emissions as shown in Table. IV, but it provides the system with a higher level of stability where the average SR percentage increases to $30.2 \%$ of load. Table. V \& Figure 2 show a summary of different costs elements, emissions and SR average percentage for the four operating modes discussed in this paper.

TABLE V SYMMARY TABLE

\begin{tabular}{|c|c|c|c|c|c|c|}
\hline \multirow{2}{*}{ Mode } & \multicolumn{4}{|c|}{ System Elements Costs (\$ ) } & Environmental Effects (tons ) & SR \% \\
\cline { 2 - 7 } & Base 10 -Units & V2G revenue & RESs & Total Cost & Emissions & Avg. \\
\hline 10 - units only & 563937 & 0 & 0 & 563937 & 26991 & 16.6 \\
\hline PHEV- V2G integra- tion & 551830 & 5858 & 0 & 557690 & 26569 & 13.7 \\
\hline \multirow{2}{*}{ Wind \& solar integra- tion } & 525159 & 0 & 25591 & & & 24485 \\
\hline All-in & 526819 & 3578 & 21893 & 552290 & 24637 & 30.2 \\
\hline
\end{tabular}

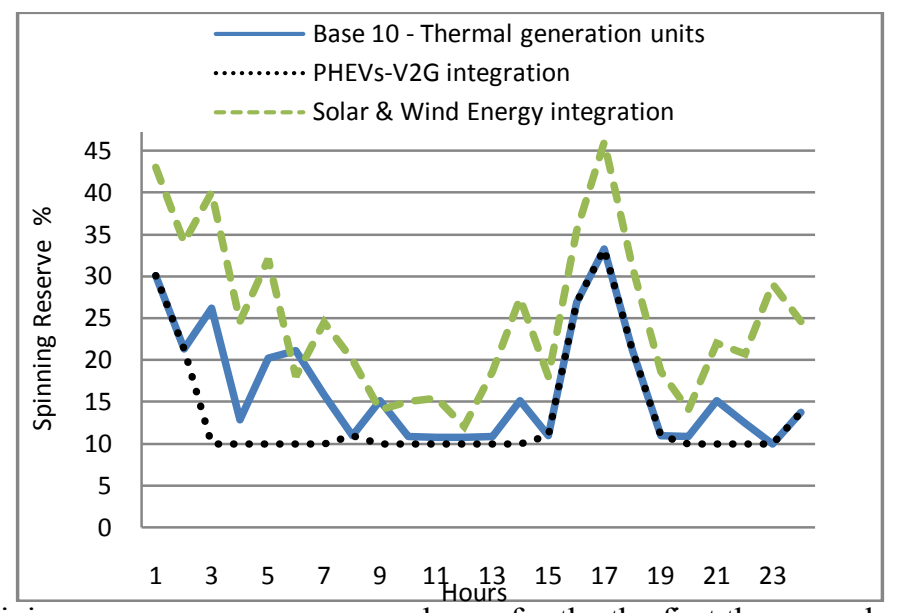

Figure 2. Spining reserve summary versus hours for the the first three modes of operation

\section{CONCLUSION}

In this paper, the unit commitment problem has been solved in four different modes, provided with results and analysis to illustrate cost and emission reductions for a sustainable integrated electricity and transportation infrastructure. The four modes were: (1) Base 10-generators, (2) PHEVs-V2G integration, (3) wind and solar energy integration, and (4) integrating PHEVs-V2G, wind and solar energy with the base 10generators model. Binary and integer Genetic Algorithm optimization has been applied on the different dynamic data of the available power sources for the four modes.

GA optimization with a new simple economic load dispatching method has been used in order to generate intelligent and efficient utilization scheduling of the available power resources. PHEVs-V2G has been used as a spinning reserve service provider where profit (revenue) to the owner is taking into consideration. In order to maintain a longer battery life-time for PHEVs-V2G, a 1 charging-discharging/day rate is considered to every vehicle. Wind and solar energy is considered to partially replace the thermal generation units. In order to present a reliable and measurable solution, pricing and costs has been included for PHEVs-V2G spinning reserve revenue, wind and solar power providing.

From this study, it is clear that:

(1) Integrating PHEVs-V2G in UC problem, gives the operator a fully controllable and quick response service for the spinning reserve.

(2) Revenue to the user while maintain a policy for a longer battery life-time, encourages vehicles' users to provide the electricity grid with the needed spinning reserve.

(3) Integrating wind and solar energy (RESs) only, increases the level of spinning reserve which leads to a more stable and reliable electricity system. 
(4) For maximum reliability of the system, both PHEVs-V2G and RESs can be integrated as this up level the spinning reserve average percentage up to $30.2 \%$.

(5) Significant cost and emissions reductions has been achieved when integrating PHEVs-V2G, RESs or both together with the base 10-generators models. In future, there is enough scope to include different load dispatching techniques, cost and emissions oriented optimization, other ancillary services besides the spinning reserve and wind and solar uncertainties calculation methods.

\section{References}

[1] A.Y.Saber, and G.K.Venayagamoorthy, "Plug-in Vehicles and Renewable Energy Sources for Cost and Emission Reductions, " IEEE Trans. on Industrial Electronics, vol. 58, no. 4, pp. 1229-1238, Apr. 2011

[2] A.Y.Saber, and G.K.Venayagamoorthy, "Efficient Utilization of Renewable Energy Sources by Gridable Vehicles in CyberPhysical Energy Systems", IEEE Systems Journal, vol.4, Issue.3, pp. 285 - 294, Sept. 2010

[3] W. Kempton, and J. Tomi'c, "Vehicle-to-grid power fundamentals: Calculating capacity and net revenue, " Journal of Power Sources, vol.144, pp. 268-279, Apr. 2005.

[4] California ISO, "Market Performance Report October 2011," CAISO, Outcropping Way Folsom, California 95630 (916) 351-4400, pp.14, Nov 2011.

[5] J.Klein, "Comparative Costs of California Central Station Electricity Generation", California Energy Commission, CEC-200-2009017-SD, pp.28, Jan 2009.

[7] California ISO, "Integration of Renewable Resources, Operational Requirements and Generation Fleet capability at 20\% RPS", pp.29, Aug 2010.

[8] http://www.nrel.gov/electricity/transmission/resource forecasting.html 